\title{
BUCHBESPRECHUNGEN
}

\author{
Abdullah Ahsan \\ The Organization of the Islamic Conference: OIC. An Introduction to an Islamic \\ Political Institution \\ International Institute of Islamic Thought, Herndon/Virginia, 1988, 141 S., US \$19.75
}

Dieses Buch ist eine recht ausführliche Darstellung der Strukturen der OIC, insbesondere auch der spezialisierten Komitees, Unterorgane und angegliederten Organisationen, und stellt so eine nützliche Ergänzung zu der bisher spärlichen Buchliteratur über sie dar.1 Abdullah Ahsan bezeichnet das auf seiner Dissertation beruhende Buch als Lehrbuch für das Grundstudium der Politikwissenschaften. Mit dieser Begründung verzichtet er bedauerlicherweise weitgehend auf Fußnoten. Der Autor geht bei seiner Betrachtung der OIC von dem Konzept der islamischen Umma aus: Dieses leitet er ausführlich her und betrachtet die Organisation nahezu ausschließlich unter dieser Leitlinie.

In zwei längeren Kapiteln stellt der Autor die Arbeit der OIC auf wirtschaftlichem und kulturellem Gebiet dar. Außer dem Mangel an Geld und der mangelnden Bereitschaft der Mitgliedsstaaten, die Resolutionen der OIC auszuführen, zeigt er dabei leider nur selten Gründe für das Scheitern der Pläne auf.

Ausfuhrlich untersucht der Autor die Rolle der OIC als Plattform für Vermittlungen und Schlichtungen zwischen Staaten. Er kommt hierbei zu dem zutreffend vernichtenden Ergebnis, daß die OIC fast immer versagt hat: Es ist Ihr z.B. nicht gelungen, im Afghanistankonflikt und im Iran-Irak Krieg erfolgreich zu vermitteln. Ein entscheidendes Hindemis hierfür sieht Ahsan in der mangelnden Einigkeit der Mitgliedsstaaten.

Für eine der strukturellen Ursachen der Schwäche der OIC, die weitgehende Konzentration auf Probleme der arabischen Welt, bringt Ahsan zwar Beispiele, versäumt es allerdings völlig, dieses Problem zu benennen.

Mit Recht wirft Ahsan den Mitgliedsstaaten vor, daß sie zahllose vollmundige Resolutionen verfassen, die selten ausgeführt werden, zumal dann nicht, wenn nationale Interessen tangiert werden können. Leider führt der Autor hier seine Kritik nicht weiter und versäumt es, zu zeigen, daß die OIC bisweilen mangelnde Unterstützung durch politischen Druck ersetzt (z.B. die Suspendierung der Mitgliedschaft Ägyptens nach dem Camp David-Abkommen).

1 Z.B. Hasan Moinuddin, Die Organisation der Islamischen Konferenz (OIC) als Forum politischer und wirschaftlicher Kooperation, Bochum, 1984 - vgl. VRÜ (19) 1986, S. 367 ff., ders.: The Charter of the Islamic Conference and Legal Framework of Economic Co-operation among its Member States: A Study, Oxford, 1987 (eine überarbeitete und erweiterte Version des Buches von 1984). 
Abgesehen von - so sein Fazit - ihrem Fortbestehen, was er als Erfolg wertet, habe die OIC ihr Ziel verfehlt. Den Grund dafür sieht er in dem Bestehen von Nationalstaaten und dem säkulären Konzept der nationalen Souveränität. Ahsan glaubt, die wahre und anzustrebende Gestalt der OIC sei die einer starken Zentralgewalt, der die Nationalstaaten untergeordnet sind. Diese vorgefaßte Ansicht hindert ihn daran, die Probleme dieser Organisation, die nur eine Art Diskussionsforum darstellt, zu analysieren. Dies entwertet das Buch derart, daß es sich weitgehend nur als deskriptive Darstellung der OIC gebrauchen läßt.

Mark Zimdars

\section{Christian Wagner}

Die Muslime Sri Lankas. Eine Volksgruppe im Spannungsfeld des ethnischen Konflikts zwischen Singhalesen und Tamilen

Amold Bergstraesser Institut, Freiburger Beiträge zu Entwicklung und Politik 5, Freiburg 1990, 251 S., DM 22,-

Entgegen den Erwartungen von Modernisierungstheoretikem ist die Bedeutung ethnischer Konflikte in Entwicklungsländern nicht zurückgegangen. Da für ihn sowohl kulturell als auch ökonomisch orientierte Ansätze nicht ausreichend zu erklären vermögen, warum die Orientierung an ethnischen Identitäten gerade in neuerer Zeit zu einem eigenständigen Phänomen geworden sind, stützt Wagners Analyse sich weitgehend auf die Gegenthese: Ethnische Konflikte werden durch Modemisierung nicht etwa überwunden, sondem umgekehrt als Folge des kolonialen und nachkolonialen Modernisierungsprozesses verstanden. Der Autor analysiert auf dieser Grundlage die Entwicklung der kleinen muslimischen Bevölkerung Sri Lankas seit vorkolonialer Zeit bis in die jüngste Vergangenheit.

In der traditionellen und weitgehend ländlichen Gesellschaft bedurfte die Identität der muslimischen Minderheit anfangs keiner besonderen Betonung. Sie ergab sich für den Einzelnen wie selbstverständlich aus seiner vorgegebenen gesellschaftlichen Rolle. Erst der Kolonialismus lieferte die modeme Idee des gemeinsamen Volkes und mit der europäischen Wissenschaft die Instrumente zu ethnischer Identifikation und Abgrenzung.

Den Muslimen im nachkolonialen Sri Lanka blieb im Gegensatz zu den Singhalesen und Tamilen als Abgrenzungskriterium lediglich die Religion, da übliche Kriterien wie Siedlungsraum, Herkunft, Kultur oder Sprache bei ihnen weitgehend versagten. Das religiös bestimmte ethnische Gemeinschaftsgefühl konnte dann von der europäisch orientierten kleinen Muslimelite an der Westküste in Colombo erfolgreich als politische Strategie eingesetzt werden. Diese Betonung der Religion zur Bildung einer modernen Gruppenidentität legte später allerdings den Rückgriff auf die Orthodoxie nahe. 